\title{
Egeo, Minos, Jacinto y Geresto: a propósito de un fragmento de la Biblioteca de [Pseudo]Apolodoro
}

\author{
Manuel ArJona PÉREZ \\ FECYT \\ Universidad Nacional y Capodistria de Atenas $^{1}$ \\ manueldecubito@hotmail.com
}

\section{RESUMEN}

[Pseudo]Apolodoro nos informa acerca de una tradición mitológica que algunos asociaban a la historia de la ofrenda humana que los atenienses enviaban periódicamente a Minos. La tradición incluye elementos que nos remiten a una amplia gama de aspectos sumamente relevantes de la religión griega, tales como la estrecha relación entre las expresiones cultuales y las competiciones atléticas, la extendida convicción de los estados helenos al respecto de la utilidad práctica de las consultas oraculares (incluso conociéndose casos de inoperancia), o el carácter liminar de los rituales de expiación.

Palabras clave: Androgeo, Geresto, Jacinto, mitos de expiación, pharmakoi.

Aegeus, Minos, Hyakinthos and Geraistos: on a fragment of [Pseudo]Apollodorus' Bibliotheca

\begin{abstract}
In this paper we examine a fragment of [Pseudo]Apollodorus pertaining to a mythological tradition linked to the story of the human offering, which was sent by the Athenians to Minos. This tradition contains elements refering to a wide range of highly important aspects of the Greek religion, such as the relationship between cult expressions and athletic contests, the conviction on the usefulness of oracular consultations (notwithstanding attested cases of unfulfilled predictions), and the liminal character of the atonement myths.
\end{abstract}

Keywords: Androgeus, Geraistos, Hyakinthos, atonement myths, pharmakoi.

SUMARIO: 1. Introducción. 2. Una transgresión en la Atenas del rey Egeo: el asesinato de Androgeo. 3. Una situación apocalíptica: guerra, hambre, peste y muerte. 4. En busca de la salvación: el sacri-

${ }^{1}$ Este trabajo ha sido realizado gracias a la financiación del Ministerio de Ciencia e Innovación, a través del Programa Nacional de Movilidad de Recursos Humanos del Plan Nacional de I+D+I 2008-2011. El autor quiere dejar constancia de su agradecimiento a los doctores M. Valdés Guía, M. del Amor López Jimeno y F. Marco Simón, así como a los especialistas que componen el Consejo de Redacción de la revista 'Ilu, por sus correcciones y sugerencias sobre determinadas cuestiones tratadas en el presente artículo. Cualquier error detectable en las páginas que siguen es responsabilidad exclusiva del autor. 
ficio de pharmakoi. 5. Honrar a un monstruo, honrar a un dios. 6. La Tumba de Geresto. 7. La ofrenda adecuada. 8. Explotando un mito. 9. Conclusión.

FECHA DE RECEPCIÓN: 20 DE 05 DE 2010 FECHA DE ACEPTACIÓN: 15 DE 11 DE 2010

\section{INTRODUCCIÓN}

En el tercer libro de la Biblioteca de [Pseudo]Apolodoro (III, 15, 7-8) encontramos un relato sobre la larga guerra que enfrentó a Minos y a los atenienses, un conflicto que estalló al poco tiempo de que el rey Egeo hubiese instaurado las fiestas de las Panateneas en el Ática. El mitógrafo cuenta detalladamente cómo se desencadenó el enfrentamiento. Androgeo, el hijo del monarca cretense, había llegado a Atenas para participar en las competiciones atléticas que se iban a desarrollar durante las citadas fiestas. La victoria del joven despierta, no obstante, la envidia de sus rivales en los agones o bien del propio Egeo, lo que a su vez provoca que los unos o el otro tramen alevosamente la muerte del extranjero. La noticia del asesinato de Androgeo llega a Minos, quien busca venganza en forma de una expedición militar contra la Grecia continental. Minos no tarda en ocupar Mégara recurriendo a un ardid que constituye un lugar común de la mitología helena: el conquistador seduce a la hija del dirigente local, y esta última, movida por el amor, traiciona familia y patria. Por el contrario, Minos no logra imponerse de forma tan fácil sobre los atenienses. Y es así que:

Como la guerra se prolongaba y no podía adueñarse de Atenas, [Minos] rogó a Zeus que castigara a los atenienses. El hambre y la peste ${ }^{2}$ afligieron a la ciudad y entonces los atenienses, obedeciendo a un antiguo oráculo, primero sacrificaron a las hijas de Jacinto, Anteide, Egleide, Litea y Ortea, sobre la tumba del cíclope Geresto; Jacinto había venido de Lacedemonia y habitaba en Atenas. Al no servir de nada el sacrificio, consultaron al oráculo cómo podrían librarse, y el dios les respondió que diesen a Minos la satisfacción que él escogiera. Por eso le enviaron emisarios y le permitieron que pidiese satisfacción. Minos ordenó enviar inermes siete muchachos y otras tantas muchachas para alimento del Minotauro (trad. de M. Rodríguez de Sepúlveda, Ed. Gredos, Colec. Biblioteca Clásica, Madrid, 1985).

En este artículo vamos a centrar la atención en el análisis del fragmento aquí plasmado, puesto que comprende una interesante y enjundiosa tradición, por nosotros marcada en cursiva, que parece constituir un «injerto» en la historia general, ampliamente difundida, de la ofrenda humana ateniense a Minos. El punto de inserción de dicha

\footnotetext{
${ }^{2}$ El término en griego antiguo que aparece en el texto de [Pseudo]Apolodoro es « «oł $\mu$ ó $»$. La tradución que tradicionalmente se ofrece de esta palabra es «peste», si bien su significado puede extenderse a cualquier pandemia. A efectos de nuestra investigación, esta circunstancia no tiene repercusiones sustanciales.
} 
tradición (que en lo sucesivo denominaremos Tradición G) es la consulta mántica formulada por los atenienses, la cual es ( $i \cos a$ extraña!) doble en el texto de [Pseudo]Apolodoro. En efecto, aquí se nos habla de un «antiguo oráculo», que no tiene resultado, seguido de un «segundo oráculo», que conducirá a la solución final del problema para los atenienses. La repetición de una interpelación oracular, bien porque la primera respuesta fuera malinterpretada, bien porque ésta resultara completamente ineficaz, no es una trama común. No se trata, para ser exactos, de un unicum, tal y como sospecha P. Bonnechere ${ }^{3}$, puesto que Tucídides menciona un caso semejante ${ }^{4}$. Constituye, sin embargo, una circunstancia atípica, sobre todo en un contexto mitológico, y esto nos pone sobre aviso de la existencia de un acoplamiento de un elemento suplementario en la leyenda de la ofrenda ateniense. El carácter de «anexo» de la Tradición $\mathrm{G}$ también queda de manifiesto al comprobar que, si se suprime su contenido (es decir, la sección que hemos marcado en cursiva) del resto del relato arriba reproducido, la línea temática troncal de este último no queda afectada en lo más mínimo. Una confirmación más de nuestras sospechas es el hecho de que, si cotejamos la narración de [Pseudo]Apolodoro con los relatos de la historia ofrecidos por Plutarco y Pausanias, vemos que ni el queroneo ni el lidio recogen la Tradición G. Plutarco y Pausanias sí mencionan, en cambio, los otros componentes del mito ${ }^{5}$.

Con todo, lo más sobresaliente de la Tradición $\mathrm{G}$ es la maestría con la que se inserta en el relato general y sobre todo la lógica interna de su desarrollo narrativo. En las páginas siguientes nos proponemos evidenciar ambos aspectos, y para ello vamos a analizar una serie de elementos que son aludidos por [Pseudo]Apolodoro y que consideramos especialmente relevantes.

\section{UNA TRANSGRESIÓN EN LA ATENAS DEL REY EGEO: EL ASESINATO DE ANDROGEO}

[Pseudo]Apolodoro relata que Androgeo, el hijo de Minos, llegó a Atenas con el objetivo de participar en los juegos atléticos organizados durante las Panateneas. Esto significa que el joven cretense tenía derecho al asilo que consuetudinariamente amparaba, por un lado, a los extranjeros de noble cuna que se desplazaban a otras tierras (en virtud de la antiquísima institución de la xenia $)^{6} \mathrm{y}$, por otro, a los competidores, theoroi y/o espectadores que acudían a cualquiera de los grandes juegos atléticos que se celebraban con periodicidad en la Grecia Antigua (en virtud de la ekecheria o las

${ }^{3}$ P. Bonnechere, Le sacrifice humain en Grèce ancienne, Athènes-Liège, 1994, p. 80.
${ }^{4}$ Th., II, 47, 4.
${ }^{5}$ Plu., Thes., XVss.; Paus., I, 27, 9-10. Véase, por el contrario, los testimonios de Diodoro (XVII, 15, 2),

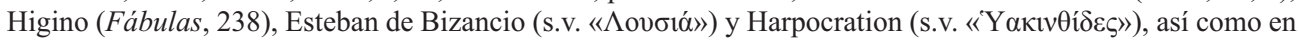
la Suda (s.v. «Y $\alpha \kappa \imath v \theta i ́ \delta \varepsilon \zeta »)$. En todos ellos es evidente un conocimiento de la Tradición G, aunque, quizás, con ciertas diferencias respecto al relato de [Pseudo]Apolodoro. Así, Higino apunta que sólo una hija de Jacinto fue sacrificada.

${ }^{6}$ Al respecto, Ph. Gauthier, Symbola. Les étrangers et la justice dans les cités grecques, Nancy, 1972, pp. $18-27$. 
spondai panhelénicas $)^{7}$. Pese a ello, Androgeo es asesinado por los adversarios a los que había derrotado en las Panateneas ${ }^{8}$, o, indirectamente, por Egeo.

El homicidio de Androgeo constituye, por consiguiente, una doble transgresión. Nos consta que los delitos de este tipo e importancia trascendían el ámbito de la justicia de los mortales y adquirirían dimensiones divinas, puesto que en la Antigüedad se consideraba que los dioses eran los garantes de la observancia de los dos principios aludidos, la xenia y la ekecheria. En efecto, que la violación del precepto de la xenia suponía una infracción seria y que acarreaba el castigo divino, es algo que podemos ver, por ejemplo, en el mito sobre las consecuencias del asesinato de Ífito a manos de su anfitrión Heracles: el semidiós, aquejado por una misteriosa enfermedad, acude primero a Neleo y a Défobo, y finalmente consulta a la Pitia en busca de una expiación que le permita purificarse de su culpa o miasma ${ }^{9}$. Por otra parte, en un fragmento de Platón se señala igualmente que todo aquél que provocaba la muerte a un participante en unos juegos atléticos, incluso de forma involuntaria, incurría en una falta gravísima. Para borrar su afrenta el culpable debía ir a Delfos y ser purificado por el oráculo. Una vez perdonado por los dioses, quedaba automáticamente absuelto ante la justicia humana ${ }^{10}$.

Para Atenas, las consecuencias del asesinato de un inocente que gozaba de protección divina se adivinan fatales. No faltan paralelos al respecto en la mitología helena. Con un miasma semejante cargaron los potnios cuando, ebrios, quitaron la vida a un sacerdote de Dioniso; o los locrios, dado que su adalid Áyax, aunque no mató a Casandra, sacerdotisa de Atenea, la forzó para que se desprendiese de la estatua votiva de la diosa en Troya. Unos y otros sufrirán duras represalias ${ }^{11}$. Las calamidades que se ciernen sobre el Ática a raíz de la muerte de Androgeo se manifiestan en un principio bajo la forma de una expedición militar decretada por Minos contra los responsables de la muerte de su hijo. Sin embargo, la amenaza no tarda mucho en adquirir dimensiones aún más graves.

\section{UNA SITUACIÓN APOCALÍPTICA: GUERRA, HAMBRE, PESTE Y MUERTE}

En la producción literaria del periodo geométrico y arcaico encontramos ya algunas alusiones a personajes como Minos, Androgeo o Egeo, así como pasajes concer-

\footnotetext{
${ }^{7}$ M. Dillon, Pilgrims and Pilgrimage in Ancient Greece, London-New York, 1997, p. 28.

${ }^{8}$ Pausanias (V, 2, 4-5) cita, pero no cree, una tradición protagonizada por dos jóvenes eleos, Filanto y Lampo, que viajaron a Istmia con el objetivo de concursar en las competiciones gímnicas locales pero que fueron asesinados, antes de llegar a su destino, por los que habrían de ser sus rivales en dichos juegos atléticos.

${ }^{9}$ Véase Hom., Od., XXI, 13-30; D.S., IV, 31, 4-5; Apollod., Bibl., II, 6, 2; Paus., X, 13, 8. Sobre el miasma, véase R. Parker, Miasma. Polution and purification in early Greek Religion, Oxford, 1983.

${ }^{10} \mathrm{Pl}$., Lg., 865a-b. Véase, en cambio, D., XXIII, 53ss. sobre la ley ateniense, que, en cualquier caso, castigaba al asesino que actuaba con premeditación.

${ }^{11}$ Sobre los potnios, Paus., IX, 8, 2; sobre los locrios, Lyc., Alejandra, passim y Apollod., Ep., V, 22 y VI, 20-22.
} 
nientes al tributo humano que los atenienses se habían visto obligados a pagar, otro$\mathrm{ra}$, al basileus cretense $^{12}$. No obstante, las referencias concretas más antiguas relativas a la guerra entablada entre Minos y los atenienses son, a nuestro conocer, bastante posteriores: además de un comentario de Platón en el que se sugiere un enfrentamiento bélico, cabe remitir a sendos fragmentos de Diodoro y Plutarco ${ }^{13}$. Sea como fuere, son numerosas las obras antiguas en las cuales se subraya cuán vasto era el imperio de Minos, que englobaba todo el Egeo: véanse por ejemplo las menciones de Baquílides, Heródoto y Tucídides ${ }^{14}$. Así pues, en el relato de [Pseudo]Apolodoro subyace la idea de que Atenas se enfrenta a una amenaza extrema, toda vez que se enfrenta a un enemigo temible ${ }^{15}$.

Con todo, [Pseudo]Apolodoro apunta que Minos se ve incapaz de reducir a los atenienses, por lo que se remite a Zeus para que éste le preste ayuda divina. Que el monarca cretense eligiese al Crónida como el destinatario de sus ruegos resulta totalmente lógico. En efecto, una de las competencias del dios era precisamente el restablecimiento de la justicia en aquellas situaciones en que esta entidad quedaba vulne$\operatorname{rada}^{16}$. Además, resulta que el asesinato de un extranjero de noble linaje constituye, como hemos dicho, una seria afrenta contra la institución de la xenia, competencia de Zeus Xenios ${ }^{17}$. En fin, resulta obvio que si alguna divinidad puede estar (pre)dispuesta a beneficiar a Minos, ésta es, sin duda, su propio padre ${ }^{18}$, a la vez que abuelo del desventurado Androgeo. Consecuentemente no nos puede extrañar que el Crónida acceda a los deseos del monarca cretense en detrimento de los atenienses, y eso a pesar de que éstos últimos lo honraban a su vez como Polieo ${ }^{19}$.

Así las cosas, el Ática es asolada primero por la guerra y después por el hambre y la peste. Los castigos aplicados por Zeus encajan a la perfección con las competen-

${ }^{12}$ Las primeras menciones a Minos y Ariadna aparecen en la Odisea (XI, 321-325 y 568-571). En la obra pseudo-hesiódica El Catálogo de las Mujeres o Eeas (véase fr. $145 \mathrm{MW}$ ) se alude a Androgeo. En la Ilíada (I, 264-265) Teseo aparece ya como hijo de Egeo. Baquílides (XVII) se refiere al viaje de Teseo desde Atenas a Creta y Safo (fr. $206 P L F$ ) alude a la liberación de los catorce jóvenes atenienses por parte de Teseo. Sobre el registro literario y las representaciones de Teseo y el Minotauro en el periodo arcaico, T. Gantz, Early Greek Myth. A Guide to Literary and Artistic Sources, Baltimore-London, 1993, pp. 259-271 y H.J. Walker, Theseus and Athens, Oxford, 1995, pp. 15-20.

13 P1., Lg., 706a-b; D.S., IV, 60 y 61; Plu., Thes., XV.

14 B., XVII, 20-29; Hdt., I, 171 y III, 122; y Th., I, 4. Sobre la imagen de los primeros imperios marítimos en Heródoto y Tucídides, E. Irwin, «The politics of precedence: first 'historians' on first 'thalassocrats'», en R. Osborne (ed.), Debating the Athenian Cultural Revolution: Art, literature, philosophy, and politics 430-380 $B C$, Cambridge, 2007, pp. 188-223.

15 Véase también Apollod., Bibl., III, 1, 3.

${ }^{16}$ Al hilo de la cuestión, cabe apuntar que los cretenses consideraban a Zeus como el autor de sus leyes (P1., Lg., 624 a). Sobre Zeus y la justicia, H. Lloyd-Jones, The justice of Zeus, Los Angeles-London, 1971.

${ }_{17}$ Para Zeus como protector de los extranjeros, véase por ejemplo Hom., Od., VII, 177-181; IX, 269-271; y XIV, 402-406. Por otro lado, en la Ilíada (III, 349-354) vemos que Menelao alza sus preces a Zeus para suplicarle que le permita castigar a Paris, alegando que el troyano que le había robado a su esposa legítima: con dicho acto, el invitado había violado claramente las normas más básicas y sagradas de la hospitalidad.

${ }^{18}$ Sobre este parentesco, Hom., Od., XI, 568-571; Hes., El Catálogo de las Mujeres o Eeas, fr. 140 MW; B., XVII, 20.

${ }^{19}$ La bibliografía del culto a Zeus Polieo en Atenas la compendia M. Valdés Guía, «La constitución de la religión cívica en Atenas arcaica (Parte Tercera)», 'Ilu 11 (2006), p. 269. 
cias que los antiguos griegos atribuían a esta divinidad. En efecto, Zeus era considerado (especialmente bajo los epítetos Ctonio y Meliquio) como un dios agrario, propiciador de la abundancia de alimentos ${ }^{20}$. Por tal razón, cualquier comunidad que perdía su favor se arriesgaba a enfrentarse a una esterilidad agraria o a «los desastres de las cosechas $\rangle^{21}$. La otra represalia que sufren los atenienses es la peste, una enfermedad que era enviada habitualmente por Apolo ${ }^{22}$, aunque también por Zeus ${ }^{23}$.

En realidad, lo que se despliega aquí es un tópico más del imaginario heleno:

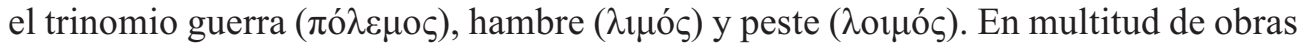
antiguas se manifiesta una clara conciencia de que estos tres males se relacionaban entre sí. Así, que los episodios bélicos provocaban hambrunas es algo que explicita Tucídides cuando alude a la stasis de los corcirenses, y Pausanias cuando habla de la Primera Guerra Mesenia ${ }^{24}$. El par guerra y peste aparece no ya sólo en obras de contenido mitológico como la Ilíada, sino también en narraciones de acontecimientos históricos: son famosos los fragmentos de Tucídides en los que se describe la peste que asoló el Ática durante la Guerra del Peloponeso ${ }^{25}$. En fin, el dúo formado por la peste y el hambre surge asimismo en los textos de Hesíodo, Sófocles y Heródoto $^{26}$.

Numerosos mitos retratan situaciones de miasma que son causadas por el asesinato de un inocente y que son castigadas por los dioses (Atenea, Dioniso, etc) meramente con plagas ${ }^{27}$. La coyuntura ateniense, en la que se combinan tres grandes males, constituye no obstante una circunstancia realmente excepcional, liminar, que transciende cualquier remedio humano. Así pues, los atenienses tienen razones más que suficientes para acudir a un oráculo y consultar los designios divinos. La expiación que se disponen a aceptar se adivina extrema, en consonancia con el crimen cometido y la grave situación que atraviesan.

${ }^{20}$ Sobre Zeus Ctonio y su culto entre los agricultores, véase Hes., Op., 465-467. Es posible que Zeus Ctonio fuera ya venerado durante el periodo protogeométrico en el Himeto, tal y como sostiene M.K. Langdon, $A$ Sanctuary of Zeus on Mount Hymettos [Hesperia Suppl. XVI], Princeton, 1976, pp. 79-95 (aunque I.S. Lemos, The Protogeometric Aegean. The Archaeology of the Late Eleventh and Tenth Centuries BC, Oxford 2002, p. 222, expresa sus dudas al respecto). Sobre Zeus Meliquio o Meiliquio, Th., I, 126, 6. Sobre su culto, N. Cusumano, «Zeus Meilichios», Mythos 3 (1991), pp. 19-47 y G.V. Lalonde, Horos Dios: an Athenian Shrine and Cult of Zeus, Leiden-Boston, 2006, passim.

${ }^{21}$ X., Ath., II, 6. Sobre la traducción de este fragmento véase H. Frisch, The Constitution of the Athenians. A philological-historical analysis of Pseudo-Xenophon's treatise De re publica atheniensium, Københaun, 1942 , p. 249.

22 Tal y como vemos en Hom., Il., I, 8-67 y Apollod., Bibl., II, 5, 9.

${ }^{23}$ Tal y como sostiene Hesíodo $(O p ., 243)$ y recuerda Esquines (III, 135). En la versión sobre la muerte de Androgeo transmitida por Plutarco (Thes., XV) se apunta que la esterilidad y la peste fueron enviadas por un daimon.

${ }^{24}$ Th., III, 85, 2; Paus., IV, 13, 5.

${ }^{25}$ Hom., Il., I, 8-67; Th., II, 49-54 y 59; III, 3, 1; VI, 12, 1 y 26, 2. Sobre situaciones de guerra y peste en el Peloponeso, Th., V, 41, 2.

${ }^{26}$ Hes., Op., 243; S., OT, 22-30; Hdt., VII, 171, 2. También Plu., Sobre Isis y Osiris, XLVII (= Moralia $370 \mathrm{~b})$.

27 Así lo vemos en los casos de los potnios y los locrios a los que nos hemos referido anteriormente. Véase Paus., IX, 8, 2 y Apollod., Ep., V, 22 y VI, 20-22. 


\section{EN BUSCA DE LA SALVACIÓN: EL SACRIFICIO DE PHARMAKOI}

La decisión de los atenienses de recurrir a la ayuda divina, plasmada en un antiguo oráculo, resulta congruente. En periodos críticos, una consulta mántica constituía una práctica recurrente: así lo ilustran, verbigracia, los testimonios de Heródoto, Plutarco y Pausanias en los que se narra cómo los quiotas, los lacedemonios, los potnios y los cleonios, al sufrir epidemias, solicitaron el consejo de Apolo a través de la $\mathrm{Pitia}^{28}$. Pausanias nos informa asimismo que los figaleos consultaron el oráculo de Delfos para librarse de una hambruna y que Ífito acudió a la misma sede para encontrar una solución a la guerra y la peste que asolaban en su época toda la Hélade ${ }^{29}$.

En el relato de [Pseudo]Apolodoro, un «antiguo oráculo» insta a los atenienses a adoptar una solución que, según la mitología helena, era aplicada en situaciones extraordinarias: el sacrificio de uno o varios pharmakoi. En efecto, según otra leyenda recogida por Licurgo, los atenientes se remitieron al oráculo de Delfos durante la guerra que los enfrentaba a Eumolpo, en busca de un consejo que les diera la victoria. Como respuesta, la Pitia les anunció que debían inmolar a una de las hijas de Erecteo $^{30}$. De igual manera, Pausanias cuenta que un oráculo asesoró a los atenienses el sacrificio de uno de los hijos de Heracles cuando el Ática, gobernada entonces por Teseo, se vio inmersa por primera vez en una guerra contra un enemigo peloponesio, Euristeo $^{31}$. Filócoro también transmite una versión de la muerte de Aglauro según la cual la hija de Cécrope decidió inmolarse al conocer que un oráculo de Apolo había asegurado que los atenienses vencerían en la guerra contra Eumolpo si uno de ellos se ofrecía como víctima propiciatoria ${ }^{32}$.

Según la Tradición G las víctimas elegidas por los atenienses para lograr la catarsis fueron las cuatro hijas de Jacinto, un héroe, éste, que procedía de Lacedemonia. Las muchachas encajan a la perfección con las características comunes que Bremmer atribuye a los «scapegoats» (literalmente, chivos expiatorios) helenos: se trata de figuras marginales, tanto por su origen (son extranjeras), como por su sexo (son mujeres) y su edad (se entiende que son jóvenes) ${ }^{33}$. Subyace además la idea de que las hijas de Jacinto no estaban casadas, es decir, que eran vírgenes, puras. Por lo tanto eran

\footnotetext{
${ }^{28}$ Hdt., VI, 27; Plu., Sobre la música, XLII (= Moralia, 1146 b-c); Paus., IX, 8, 2 y X, 11, 5.

${ }^{29}$ Paus., VIII, 42, 5-7 y V, 4, 6.

${ }^{30}$ Lycurg., Leoc., 98. Por el contrario, Eurípides (Ph., 852ss.) atribuye la profecía a Tiresias. El dramaturgo ateniense retoma la historia en su Erecteo, obra que ha llegado hasta nosotros de manera muy fragmentaria: R. Kannicht (ed.), Tragicorum Graecorum Fragmenta, Vol. 5.1, Göttingen, 2004, fr. 349-370. Véase además una noticia de Demarato $(F G r H 42, \mathrm{~F} 4)$ en la cual se dice que el sacrificio se realizó en honor a Perséfone. En fin, Higino afirma que el sacrificio de la hija de Erecteo fue exigido por Poseidón (Fábulas, 46), si bien hace referencia igualmente a unos oráculos (Fábulas, 238).

${ }^{31}$ Paus., I, 32, 6-7. También sobre esta historia E., Heracl., passim. Aquí la acción se desarrolla durante el reinado de Demofonte.

32 Philoch., FGrH 328, F 105. Sobre el sacrificio de jóvenes pharmakoi, véase en general J. Larson, Greek Heroines Cults, Wisconsin, 1991, pp. 15 y 101-103; P. Bonnechere, Le sacrifice humain ..., op. cit., pp. 79ss.; U. Kron, «Patriotic Heroes», en R. Hägg (ed.), Ancient Greek Hero Cults, Stockholm, 1999, pp. 78-83.

${ }^{33}$ J.N. Bremmer, «Scapegoat Rituals in Ancient Greece», (reeditado) en R. Buxton (ed.), Oxford Readings in Greek Religion, Oxford, 2000, pp. 271-293.
} 
idóneas para «limpiar» un situación de impureza, de miasma. Además, los nombres que tienen algunas de ellas, registrados cuidadosa y deliberadamente por [Pseudo]Apolodoro, dan a entender que eran víctimas valiosas, por su belleza (Anteide es «la floreciente», «la florecida», Egleide es «la resplandeciente», «la radiante») y su porte (Ortea es, quizás, «la correcta», «la erguida» o «la bien compuesta»). Se asemejan, pues, a los $\tau \varepsilon \dot{\lambda} \varepsilon ı \alpha \zeta \tilde{\omega} \alpha$ con los que los oferentes debían agasajar a las divinidades, tal y como recomendaba la norma sacrifical reflejada por autores como Aristóteles ${ }^{34}$. El objetivo perseguido es la redención del Ática, un propósito que quizás se evidencia en el nombre de la cuarta joven, Litea (quizás «la salvadora») ${ }^{35}$. Llegamos a discernir, en fin, semejanzas importantes entre las figuras de Androgeo y las hijas de Jacinto. En efecto, el uno y las otras son jóvenes, extranjeros en suelo ático, de buen porte ${ }^{36}$ y encuentran la muerte a manos de los atenienses aun cuando eran inocentes.

Pero ¿por qué fueron sacrificadas las hijas de Jacinto en concreto?. Preliminarmente hemos de apuntar que este personaje mitológico fue conocido bajo dos manifestaciones diferentes. Mientras que en una adoptaba la apariencia de un adulto barbado $^{37}$, en otra se mostraba como un joven que fue amado por Apolo y que murió de forma trágica, transformándose su sangre en la flor homónima ${ }^{38}$. Es posible que algunas leyendas postulasen que Jacinto fue criado por la mismísima Ártemis, diosa de la vida salvaje, de la flora y la fauna, y protectora de infantes y adolescentes ${ }^{39}$. Numerosos investigadores ven en la figura de Jacinto una divinidad antiquísima de la vegetación relacionada con el ciclo de la regeneración anual: un símbolo del poder de la naturaleza que es capaz de superar una situación crítica, la muerte/ el invierno, y reaparecer inaugurando una nueva época de fertilidad, a saber, la primavera/ el verano. Así, Nilsson, seguido de Mellink y Dietrich, equiparan a Jacinto con Zeus al considerar a ambos como representaciones del «Divine Child» que fue criado por divinidades vinculadas a la fuerza generadora de la Tierra ${ }^{40}$. En virtud de esta interpretación resulta totalmente lógico que el dios de la vegetación Jacinto tuviera, como postula-

\footnotetext{
${ }^{34}$ Fr. 101 Rose (=Ath., XV, 674 f).

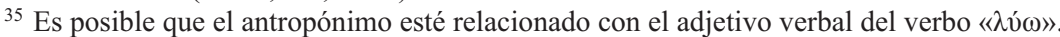

${ }^{36}$ Androgeo vence en las competiciones de las Panateneas, por lo que se adivina su excelencia física.

${ }^{37}$ Paus., III, $19,4$.

${ }^{38}$ Véase entre otros Eurípides (Hel., 1468-1473) y el mismo [Pseudo]Apolodoro (Bibl., I, 3 , 3 y III, 10, 3). Sobre la transformación de la sangre del joven Jacinto en flor, Ovid., Met., X, 162-219. M. Moreno Conde («Flor y ritos de infancia en la antigua Grecia: azafrán, narciso y jacinto», en R. Olmos, P. Cabrera y S. Montero Herrero (coords.), Paraíso cerrado, jardín abierto. El reino vegetal en el imaginario religioso del Mediterráneo, Madrid, 2005, pp. 125-145) subraya que las referencias más antiguas conservadas hasta nosotros relativas a la transformación de la sangre de Jacinto en flor se remonta al s. IV a.C.

${ }^{39}$ Numerosos documentos se refieren al culto de Ártemis Jacintótrofa en Cnido: entre ellos una inscripción incisa en uno de los muros del Tesoro de los Cnidios en Delfos (É. Bourguet, Fouilles de Delphes, III, 1, Paris, 1929, $\mathrm{n}^{\circ}$. 308). Véase al respecto G. Pugliese Carratelli, «Epigrafi di Cos relative al culto di Artemis in Cnido e in Bargylia», PP 42 (1987), pp. 110-123. Se ha sostenido que este culto pudo haber existido también en Taranto, otra colonia lacedemonia: G. Pugliese Carratelli, «Artemis Hyakinthotrophos a Taranto?», PP 55 (1989), pp. 463-469.

${ }^{40}$ M.P. Nilsson, The Minoan-Mycenaean Religion and its survival in Greek Religion. Second Revised Edition, Lund, 1950, pp. 556ss; M.J. Mellink, Hyakinthos, Utrecht, 1943, passim; B.C. Dietrich, The Origins of Greek Religion, Berlin-New York, 1974, pp. 13ss.
} 
ba la Tradición G, una hija llamada Anteide, «la florecida». Se antoja igualmente congruente que, ante un contexto de muerte y destrucción, los atenienses sacrificaran una muestra del poder engendrador de Jacinto que crecía en suelo ático, con la esperanza de que dicho acto propiciara la superación de la crisis: un ejemplo más del tópico pars pro toto que regía la práctica votiva de los antiguos griegos.

Determinados estudiosos también subrayan que la figura de Jacinto estaba vin-

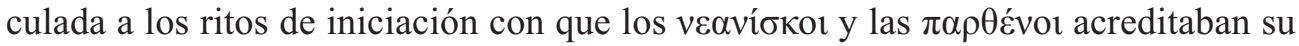
transición a la madurez, «muriendo» definitivamente como infantes y «renaciendo» como $\pi$ o $\lambda i \tau \varepsilon \varsigma$ у $\gamma v v \alpha \tilde{\kappa} \kappa \varepsilon \varsigma \pi 0 \lambda \imath \tau \tilde{\omega} v^{41}$. En numerosas ocasiones se ha señalado que los ritos de iniciación helenos contenían, de hecho, elementos que remitían al ámbito funerario ${ }^{42}$.

El culto a Jacinto está atestiguado en numerosas regiones de Grecia. En Lacedemonia (esto es, la patria de Jacinto, tal y como puntualiza la Tradición G) se celebraban las fiestas de las Jacintias ${ }^{43}$. En el marco de estas festividades el héroe era honrado con

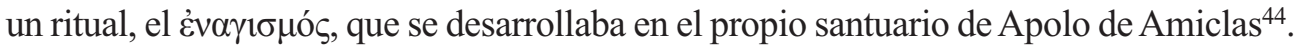
Como explica Pettersson, la denominación de la ceremonia remite al ámbito temático de la contaminación y la posterior expiación que conducía a la purificación. Seguramente el ritual también se relacionaba con los conceptos de transición y muerte, ya que se realizaba a través de una puerta de bronce ubicada a la izquierda del altar de Apolo, lugar de enterramiento del propio Jacinto. Cabe añadir que durante las Jacintias se cantaban peanes, probablemente en honor de Apolo ${ }^{45}$. Los lacedemonios entonaban estas composiciones no sólo en eventos de carácter sacro, sino también en contextos bélicos ${ }^{46}$. Los peanes eran cantados asimismo por todas aquellas comunidades griegas que sufrían una plaga, a fin de implorar la ayuda divina (por lo general la de Apolo) ${ }^{47}$. De todo lo dicho se sigue que los peanes estaban vinculados a momentos críticos en los que la cotidianidad y el orden quedaban trastocados ${ }^{48}$. Brulé ha subrayado los paralelismos que existen entre los elementos que integran las Jacintias lacedemonias y las Panateneas áticas ${ }^{49}$, esto es, las festividades que, a decir de [Pseudo]Apolodoro, fueron fundadas por Egeo $^{50}$ y mancilladas por la muerte de Androgeo.

${ }^{41}$ H. Jeanmaire, Couroi et Courètes, 1939, pp. 526-531; A. Brelich, Paides e Parthenoi, Roma, 1969, especialmente pp. 141-148.

${ }^{42}$ La bibliografía al respecto es ingente: baste citar aquí las obras de M. Eliade, Rites and Symbols of Initiation: The Mysteries of Birth and Rebirth, London, 1958, p. XII; A. Brelich, Paides e Parthenoi, op. cit., p. 33; y R. Seaford, «The tragic wedding», JHS 107 (1987), pp. 106-130.

${ }^{43}$ Heródoto (IX, 7-11), Tucídides (V, 23, 4-5) y Ateneo (IV, 139 d-f), entre otros autores, se refieren a ellas.

${ }^{44}$ Paus., III, 19, 3.

45 X., $H G, \mathrm{IV}, 5,11$.

46 Plu., Lyc., XXII, 3-6.

${ }^{47}$ Lo vemos en la Ilíada de Homero (I, 472-474) y en el Edipo Rey de Sófocles (4-5).

${ }^{48}$ M. Pettersson, Cults of Apollo at Sparta. The Hyakinthia, the Gymnopaidiai and the Karneia, Stockholm, 1992, pp. 9-41.

49 P. Brulé, «Fêtes grecques: périodicité et initiations. Hyakinthies et Panathénées», en A. Moreau (éd.), L'initiation. Tome I. Les rites d'adolescence et les Mystères, Montpellier, 1992, pp. 13-38.

${ }^{50}$ En cambio Helánico de Lesbos ( $F G r H 4$, F 39), Androtio de Atenas ( $\left.F G r H 324, \mathrm{~F} 2\right)$ y Aristóteles (fr. 637 Rose) atribuyen su fundación a Erectonio. 
Al parecer los compatriotas de Minos que vivían en el periodo clásico también rindieron culto a Jacinto: una inscripción de mediados del s. V a.C. atestigua que en Cnosos se celebraban unas fiestas llamadas Jacintias ${ }^{51}$. Desgraciadamente no sabemos si durante los festejos se desarrollaban rituales apotropaicos o de transición, ni si se trataba de una expresión cultual de gran antigüedad. Por lo que atañe al Ática, una inscripción del s. I d.C. (IG II ${ }^{2}, 1035$, línea 52) descubierta en la Acrópolis ateniense menciona un altar llamado Jacintion. Algunos investigadores, como Larson, prefieren no avanzar ninguna hipótesis arriesgada sobre la ubicación de este recinto sagrado ${ }^{52}$; en cambio, otros especialistas sostienen que el Jacintion se levantaba muy cerca del lugar de hallazgo del testimonio epigráfico, en un monte del que hablaremos más adelante.

Por el momento volvemos al ámbito mitológico para hacernos eco de la observación de Bremmer relativa a la presencia de elementos florales/vegetales en numerosos relatos sobre víctimas expiatorias ${ }^{53}$. Este componente se manifiesta doblemente en la Tradición G, dado que en ella se nos habla no sólo de Jacinto, sino también de su hija Anteide (literalmente, «la florecida») $)^{54}$.

En el texto de [Pseudo]Apolodoro se mencionan, pues, a las hijas de Jacinto,

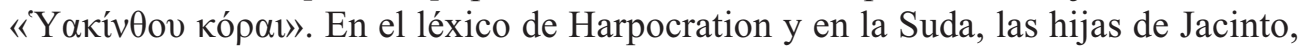

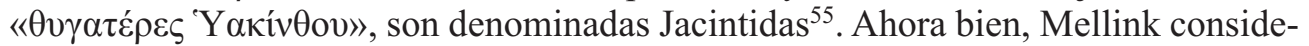
ra que las Jacintidas pudieron haber sido consideradas originalmente, no como las hijas de Jacinto, sino como sus nodrizas o asistentes, míticas o reales. Como apoyo a su hipótesis, la investigadora se remite al ejemplo de las Dionisiadas de Esparta, que no eran las hijas de Dioniso, sino las vírgenes que lo honraban participando en las competiciones de dromos dedicadas al dios del vino ${ }^{56}$.

En este punto cabe apuntar que otra tradición antigua, recogida (¿y parcialmente tergiversada?) por Eurípides en su obra Erecteo, narraba cómo las hijas de Erecteo pasaron a denominarse Jacintidas una vez que éstas se inmolaron voluntariamente para que Atenas se alzase vencedora en su guerra contra Eumolpo ${ }^{57}$. Fanodemo nos aporta más informaciones sobre esta versión, al explicar que el nombre adoptado post mortem por las muchachas se debía al hecho de que su sacrificio tuvo lugar en un monte llamado Jacinto ${ }^{58}$. Determinados investigadores ubican precisamente en este altoza-

\footnotetext{
${ }^{51}$ ICr I, 8, 4a, línea 17. Para su comentario y traducción, H. van Effenterre y F. Ruzé, Nomima. Recueil d'inscriptions politiques et juridiques de l'archaïsme grec, I, Paris, 1994, nº. 54.

52 Véase J.L. Larson, Greek Heroine ..., op. cit., pp. 102 y n. 8, 153-154.

53 J.N. Bremmer, «Scapegoat Rituals ...», op. cit., pp. 271-293.

${ }^{54}$ Nos preguntamos asimismo si el nombre de Litea, la cuarta hija de Jacinto, podría evocar en la mente de

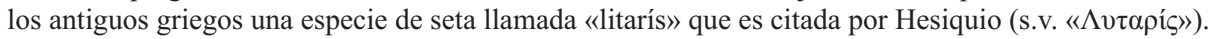

${ }^{55}$ Harp., s.v. «Y $\alpha \kappa \imath v \theta i ́ \delta \varepsilon \varsigma » ;$ Suda, s.v. «Y $\alpha \kappa \imath v \theta i ́ \delta \varepsilon \varsigma »$.

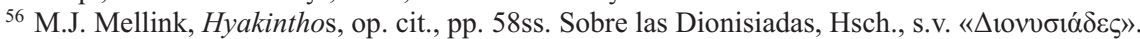

57 C. Collard, M.J. Cropp y K.H. Lee (eds.), Euripides. Selected Fragmentary Plays. Vol. I, Warminster, 1995, Erechtheus, fr. 370, 73-74; R. Kannicht y S. Radt (ed.), Tragicorum Graecorum Fragmenta, Vol. 5.1, Göttingen, 2004, Erechtheus, fr. 370, 73-74.

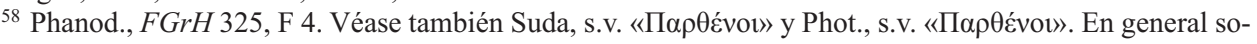
bre el tema, E. Kearns, The Heroes of Attica, London, 1989, pp. 201-202.
} 
no el altar Jacintion citado en la inscripción del s. I d.C. arriba aludida ( $\mathrm{IG} \mathrm{II}^{2}, 1035$, línea 52). En opinión de estos estudiosos, el recinto sacro estaría dedicado no sólo a Jacinto, sino también a las Jacintidas. Posteriormente expondremos sus hipótesis relativas a la identificación del Monte Jacinto con una colina que nos es más conocida bajo otro apelativo.

Unas Jacintidas aparecen mencionadas, asimismo, en una inscripción ática de finales del s. V a.C. que contiene parte de un calendario sacrifical ${ }^{59}$. En el epígrafe se estipula concretamente que se debían consagrar ciertas ofrendas en honor a las Jacintidas el noveno día de un mes cuyo nombre, por desgracia, no ha llegado hasta nosotros. A partir de varias lucubraciones, Robertson (autor que pone énfasis en la identificación de las Jacintidas aquí nombradas con las hijas de Erecteo) llega a la conclusión de que la ofrenda se desarrollaba en Esciroforión. De hecho, el duodécimo día de este mes se celebraban en Atenas las fiestas de las Esciras, a saber, el marco en el cual se conmemoraba la guerra de Atenas, liderada por Erecteo, contra Eumolpo. En lo concerniente al sacrificio en honor a las Jacintidas, Robertson habla de un rito ligado a un culto de fertilidad y del ciclo agrario: temáticamente, estaría relacionado con las Esciras, un festival de la siega. La entrega de presentes a unas heroínas/ninfas tendría lugar en verano, durante el último mes del año ateniense: es decir, en un periodo de transición ${ }^{60}$.

En fin, ciertos ecos de la Tradición G plasmada por [Pseudo]Apolodoro resuenan igualmente en un fragmento de Heladio que se ha conservado gracias a la labor recopilatoria de Focio de Constantinopla ${ }^{61}$. En efecto, el autor del s. IV d.C. apuntaba que los atenienses eligieron por primera vez pharmakoi a raíz de la peste desencadenada por la muerte de Androgeo el cretense. Ahora bien, Heladio no explicitaba los nombres de estas primeras víctimas expiatorias; y además, al hablar de la costumbre de cariz apotropaico establecida en Atenas desde aquel entonces, fijaba en dos, y no en cuatro, los pharmakoi elegidos.

\section{HONRAR A UN MONSTRUO, HONRAR A UN DIOS}

Pero volvamos a centrarnos en la Tradición $\mathrm{G}$ tal y como aparece plasmada por [Pseudo]Apolodoro. El mitógrafo dice, lo hemos visto, que los atenienses sacrificaron a las cuatro hijas de Jacinto. Sería de esperar que las jóvenes hubieran sido consagradas a Androgeo, puesto que las desgracias que afligían el Ática se desencadenaron a raíz de la muerte del hijo de Minos. Sin embargo, para sorpresa nuestra el personaje agasajado es otro. La noticia resulta aún más extraña por cuanto que Androgeo con-

\footnotetext{
${ }^{59}$ Inscripción Agora I, 7577, cara B, líneas 16ss. Al respecto, L. Gawlinski, «The Athenian Calendar of Sacrifices: A New Fragment from the Athenian Agora», Hesperia 76 (2007), pp. 47-53.

${ }^{60}$ N. Robertson, Religion and Reconciliation in Greek Cities: the Sacred Laws of Selinous and Cyrene, Oxford, 2009, pp. 170ss. y 208ss. También id., "Athena's Shrines and Festivals», en J. Neils (ed.), Worshipping Athena. Panathenaia and Parthenon, Wisconsin-London, 1996, pp. 52ss.

${ }^{61}$ R. Henry, Photius. Bibliothèque, Vol. VIII, Paris, 1977, p. 182 (§ 279, 534a).
} 
taba con un altar en el Falero y con un heroon en el Cerámico ${ }^{62}$. La ofrenda tampoco se realiza en honor de Zeus, la divinidad con la que teóricamente los atenienses debían reconciliarse para librarse de la peste y el hambre que los atenazaba. El ser al que son inmoladas Anteide, Egleide, Litea y Ortea es un enigmático cíclope de nombre Geresto. ¿Quién es este personaje? ¿Y por qué el homenajeado es él?.

En un principio, la presencia de un cíclope en el relato parece concordar con la lógica general de la Tradición G, en la que domina lo liminar, lo marginal, lo extraordinario. En efecto, hasta ahora hemos visto que a) el contexto de la historia, a saber la concomitancia de guerra, hambre y peste, constituye una situación extrema; b) la solución a esta crisis es buscada a través de una consulta a un oráculo, punto de contacto entre lo humano y lo sobrehumano; c) el remedio recomendado constituye una acción radical, drástica, el sacrificio de varias muchachas; y d) las víctimas elegidas se revelan igualmente como figuras marginales de la sociedad ateniense, puesto que son hijas de un extranjero. Con los elementos del mito que acabamos de mencionar se acomoda plenamente el hecho de que la inmolación de las jóvenes se celebrase en la tumba de un ser perteneciente a una raza que residía y actuaba en ámbitos limítrofes. Semejante caracterización es válida para los tres grupos de cíclopes que distingue Helánico ${ }^{63}$, a saber: a) «los mismos dioses», entendiéndose como tales a Bronte, Estéropes y Arges, los hijos de Urano y Gea que mencionan Hesíodo, Istro y Apolodoro ${ }^{64}$; b) los constructores de murallas, de fuerza sobrehumana, que son aludidos por Píndaro, Baquílides y Ferécides entre otros ${ }^{65}$; y c) los temibles compañeros de Polifemo que son descritos en la Odisea. No obstante, si profundizamos en las características de los componentes de cada una de estas estirpes nos encontramos con que ninguna de ellas mantiene relaciones estrechas con posibles procesos de purificación y/o regeneración, los objetivos que persiguen los atenienses.

Cierto es que los cíclopes de los dos primeros grupos son retratados como personajes industriosos y aprovechables; pero tal cosa no implica que también fueran considerados como exclusivamente benignos. Robertson sostiene que, en general, los nombres de los cíclopes (Bronte, Estéropes, Arges, Geresto) «are [...] redolent of storm: they personify the threat of bad weather» ${ }^{66}$. En virtud de esta visión, se podría deducir que los atenienses sacrificaron a las hijas de Jacinto (esto es, una pequeña muestra del poder generador de la naturaleza) en honor de un daimon de las inclemencias porque suponían que así lo calmarían y asegurarían la prosperidad del resto del acopio humano y alimenticio del Ática. Pero una ofrenda a una criatura semejante resulta, en nues-

\footnotetext{
${ }^{62}$ Sobre el altar en el Falero, véase Paus., I, 1, 4; sobre el heroon en el Cerámico, Ameleságoras de Atenas,

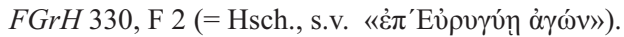

${ }^{63}$ Hellanic., $\mathrm{FGrH} 4$, F 88.

${ }^{64}$ Hesíodo (Th., 140 y 501-506) apunta que los cíclopes que nacieron de la unión de Urano y Gea fueron los forjadores de los rayos de Zeus. Istro (FGrH 334, F 71) los considera como los primeros seres que fabricaron armas de bronce. En fin, [Pseudo]Apolodoro (Bibl., I, 1, 2; I, 2, 1) narra que los cíclopes regalaron a los hijos de Cronos las poderosas armas con las que éstos vencieron a los titanes: los rayos de Zeus, el yelmo de Hades y el tridente de Poseidón.

${ }^{65}$ Pi., Fr. 169a, 7 Snell; B., XI, 77; Pherecyd., FGrH 3, F 12.

${ }^{66}$ N. Robertson, Religion and Reconciliation..., op. cit., p. 208.
} 
tra opinión, una acción algo inconexa con el problema concreto al que se enfrentan los compatriotas de Egeo en la Tradición G: las calamidades que estos últimos afrontan no son las tormentas, sino la conjunción de la guerra, la peste y el hambre.

De los cíclopes del tercer grupo tenemos una imagen aún más negativa, la ilustrada en el libro noveno de la Odisea. En la obra homérica estos personajes son seres que lindan entre lo humano y lo salvaje. De ellos se nos dice que residían en las montañas de su isla, que se dedicaban a la recolección (pero no al cultivo) de frutos y al pastoreo de cabras, y que vivían sin someterse a ley alguna. Su comportamiento incluía acciones reprobables, hasta tal punto que el propio Polifemo no tiene reparos en saciar su hambre engullendo a dos compañeros de Odiseo ${ }^{67}$. Con esta imagen se aviene la narración de [Pseudo]Apolodoro, en la que otro cíclope, Geresto, ha de quedar satisfecho si sobre su tumba se derrama sangre humana, en este caso la de cuatro jóvenes. Por otro lado, merece ser añadido que, de igual manera que encontramos semejanzas entre las hijas de Jacinto y Androgeo, podemos ver similitudes entre los comportamientos inhospitalarios de Egeo/los atenienses y Polifemo: si los primeros matan a Androgeo, un joven extranjero, el segundo (y por extensión sus congéneres) asesina a dos navegantes ítacos. En ambos casos se produce una violación de la institución de la xenia. Ahora bien, no vemos ninguna razón por la cual los atenienses coetáneos de Egeo podrían haber considerado que un sacrificio en loor de un cíclope de la estirpe de Polifemo restituiría el antiguo orden y propiciaría la regeneración de la vida en el Ática. En consecuencia, para avanzar en nuestras indagaciones no nos queda más remedio que descender de lo genérico a lo individual y centrar la atención en el propio Geresto.

La identidad de este ser da pie a numerosos interrogantes. Aparte de la cita de [Pseudo]Apolodoro, los únicos testimonios en los cuales se menciona explícitamente un personaje mitológico llamado Geresto son dos lemas de Esteban de Bizancio ${ }^{68}$. Aquí se apunta que Geresto y sus hermanos, Ténaro y Calauro, fueron unos vástagos de Zeus: descubrimos por consiguiente un vínculo familiar entre un Geresto y la divinidad que castiga a los atenienses por la muerte de Androgeo. El problema que surge es que Esteban de Bizancio no describe a Geresto, Ténaro y Calauro como cíclopes, y además no vincula a Geresto con el Ática. Bien al contrario, el lexicógrafo sostiene que el nombre de este Geresto fue aplicado a una kome (comarca) de Eubea donde se alzaba un santuario de Poseidón. Y en efecto, ya en la Odisea se dice que Néstor, Diomedes y Menelao sacrificaron en la playa de Geresto numerosos toros para agradecer al dios del mar la protección que les había dispensado durante su viaje de retorno desde Troya. Fuentes posteriores describen este lugar como un importante puerto de la costa sudeste de Eubea, y certifican la existencia en él de un santuario liminar, dispensador de asilo, que estaba dedicado a Poseidón Gerestio ${ }^{69}$.

\footnotetext{
${ }^{67}$ Para una interpretación de la imagen de los cíclopes dada en la Odisea, según la cual Polifemo constituye una excepción a la norma, véase R. Mondi, «The Homeric Cyclops: Folktale, Tradition, and Theme», TAPhA 113 (1983), pp. 17-38.

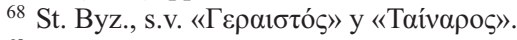

${ }^{69}$ Hom., Od., III, 165-185; Th., III, 3, 5; E., Cyc., 290-296; Ar., Eq., 561; X., HG, III, 4, 4; Scyl., 58; Str., $\mathrm{X}, 1,2$ y 7 .
} 
¿Es acertado pensar que un antropónimo Geresto generó un topónimo Geresto? El sufijo -sto(s) al final del término indica un origen prehelénico de este último ${ }^{70}$. La terminación aparece también en palabras antiquísimas como Lícasto, Festo, Caristo, Disto, Anáflisto, Macisto. Todas ellas corresponden a lugares que, en muchos casos, dieron nombre a héroes epónimos míticos. Es decir, los topónimos generaron antropónimos, y no al revés como sostiene Esteban de Bizancio ${ }^{71}$. Ahora bien, en el Etymologicum Magnum la palabra «Geresto» (que aquí designa el topónimo euboico) se

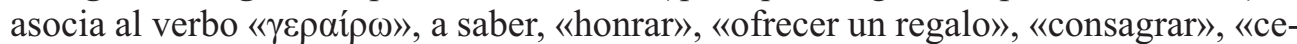
lebrar un sacrificio» $»^{72}$. En este mismo léxico se alude igualmente a un pequeño asentamiento de Arcadia denominado «Gerestion». La palabra «Gerestion» se relaciona

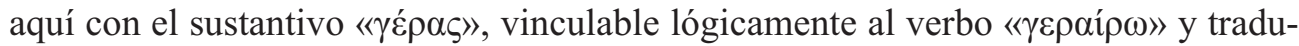
cible como «regalo» (hecho en contextos cultuales, fúnebres, de hospitalidad, etc) o incluso como «privilegio». En Gerestion de Arcadia, añade el Etymologicum Mag$n u m$, Zeus fue «envuelto en pañales» ${ }^{73}$. Nos encontramos en consecuencia ante una tergiversación etimológica que pudo haber nacido por la similitud de los términos

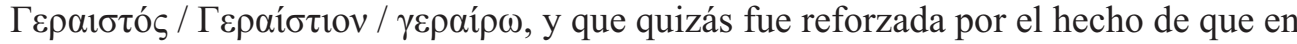
Geresto y Gerestion se celebraban actividades cultuales ${ }^{74}$.

Existen de hecho numerosas palabras que etimológicamente son vinculables al término «Geresto» y que remiten a la esfera religiosa, aparte del ya mencionado Gerestion $^{75}$. Así, una inscripción ática de finales del s. V a.C. da constancia de un culto a las

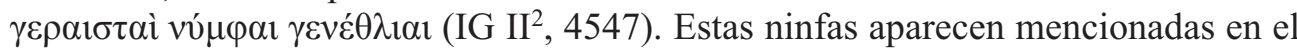
testimonio epigráfico junto a otras divinidades natalicias y curotróficas, como Leto, Ártemis Loquia e Ilitía ${ }^{76}$. Por otra parte, en el Etymologicum Magnum se apunta que en Gortina de Creta se creía que unas ninfas llamadas Gerestiadas criaron a Zeus cuando éste era un infante ${ }^{77}$. Las Gerestias, a su vez, eran unas competiciones celebradas en Geresto de Eubea por todos los autóctonos, en honor a Poseidón y en conmemoración de unos eventos que ocurrieron en invierno (o durante una tormenta) ${ }^{78}$. Gerastios/Gerestios es el nombre de un mes que está atestiguado en los calendarios de Cos y Calauria, así como en los de Trecén y Esparta/Lacedemonia, las poleis de origen de

${ }^{70}$ F. Rodríguez Adrados, «Hacia una teoría de la ciencia toponímica», Revista Española de Lingüistica 32.1 (2002), p. 45.

${ }^{71}$ Esta inversión es muy común en la obra de Esteban de Bizancio. Así, Caristo en Eubea y Lícasto en Creta, dos asentamientos citados en la Ilíada (II, 539 y 647), parecen haber dado nombre respectivamente a los héroes Caristo y Lícasto, y no al revés, tal y como pretende el lexicógrafo (s.v. «Ká

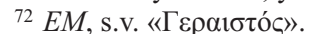

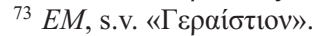

${ }^{74}$ Debemos subrayar, no obstante, que en griego antiguo el nominativo del sustantivo «Geresto» aparece en [Pseudo]Apolodoro como una palabra proparoxítona; en los lemas de Esteban de Bizancio como una palabra proparoxítona u oxítona; y en la entrada del Etymologicum Magnum como una palabra oxítona.

${ }^{75}$ Excluimos aquí el estudio pormenorizado de los antropónimos que contienen la partícula Geres-/Geras: su enumeración y dispersión geográfica no aportan datos suplementarios a la cuestión que nos atañe.

${ }^{76}$ J.L. Larson, Greek Nymphs. Myth, Cult, Lore, Oxford, 2001, pp. 132-134; M. Dillon, Girls and Women in Classical Greek Religion, London-New York, 2003, pp. 24-25.

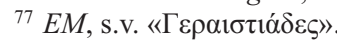

${ }^{78}$ Sch. Pi., Ol. XIII, 159 a y b. 
Teseo y Jacinto respectivamente ${ }^{79}$. Trümphy parece identificarlo (al menos en Esparta) con nuestro enero/febrero ${ }^{80}$. Podría deducirse que en cada uno de estos ámbitos geográficos el mes incluía unas fiestas que se designaban Gerastias/Gerestias. Por desgracia desconocemos qué tipo de celebraciones serían éstas. Lo único que podemos decir es que, según Ateneo, en Trecén el mes de Gerestios incluía unas fiestas (imaginamos que las Gerestias), de inversión, en las que amos y esclavos intercambiaban por un día sus papeles en la sociedad ${ }^{81}$.

¿En que medida se relacionan todos estos datos entre sí?. Lerat ${ }^{82}$ sostiene que Geresto fue originalmente un término que designaba un lugar de Eubea, sede de un santuario de Poseidón. El topónimo habría dado nombre al héroe Geresto, un «genio de promontorio» tal y como lo caracteriza el investigador francés. Este personaje mitológico, un hijo de Zeus según la tradición transmitida por Esteban de Bizancio, pudo haber sido identificado en la antigüedad con el cíclope Geresto que cita [Pseudo]Apolodoro. Por su parte, las ninfas Gerestiadas de Creta y las Gerestás del Ática serían divinidades protectoras de la regeneración y la infancia que habrían vivido en grutas o bosques. Similares a ellas habrían sido las nodrizas que previsiblemente se encargaron de cuidar a Zeus en Gerestion de Arcadia. Según Lerat estas ninfas no tendrían ninguna relación con el topónimo/antropónimo Geresto, dada la inexistencia de elementos comunes en las características/competencias atribuibles a las primeras y al segundo. En fin, las posibles fiestas Gerastias celebradas durante el mes de Gerastios/Gerestios en Cos, Calimna, Trecén y Lacedemonia, al marcar el inicio de la primavera, podrían haber estado relacionadas con el campo de actuación de las Gerestiadas y las Gerestás. Lerat no descarta, sin embargo, que las fiestas hubieran tenido alguna vinculación con Poseidón Gerestio.

Mellink $^{83}$ considera sinónimos los dos epítetos que caracterizan a las ninfas en la

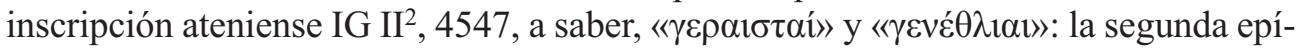
clesis («natalicias») estaría simplemente aclarando el significado de la primera. En vir-

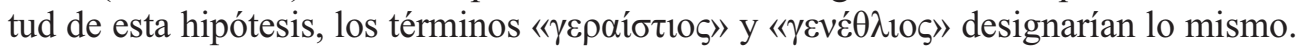
Teniendo además en cuenta que, según el Etymologicum Magnum, Gerestion de Arcadia fue un lugar donde Zeus fue criado y que las Gerestiadas de Creta fueron unas ninfas nodrizas, Mellink plantea otro silogismo, que Geresto fue un niño recién nacido. Ahora bien, a esta figura infantil le habría sobrevenido la muerte, por lo que habría sido enterrado. En otras palabras, Geresto y Jacinto no sería más que dos manifestaciones de una misma figura, la del «Divine Child» que simboliza la regeneración

\footnotetext{
79 Para Cos, M. Segre, Iscrizioni di Cos, Roma, 1993, inscripciones ED 45A.1; ED 58.6; ED 62 (A).4; ED 145(A).41; para Calauria, IG IV, 841, línea 12; para Trecén, Ath., XIV, 639 c; y para Lacedemonia, Th., IV, 118-119.

${ }^{80}$ C. Trümpy, Untersuchungen zu den altgriechischen Monatsnamen und Monatsfolge, Heidelberg, 1997, passim.

81 Ath., XIV, 639 c. En Trecén, una inscripción que es fechada en torno al 148 a.C. menciona a unos Gerestiastas, posiblemente una fratría (IG IV, 757b, 1. 12).

${ }^{82}$ L. Lerat, «Geraistos et les Geraistai», RA 25 (1946), pp. 196-203.

${ }^{83}$ M.J. Mellink, Hyakinthos, op. cit., pp. 56-69.
} 
tras la muerte. Son identificables, por lo tanto, con el propio Zeus, cuyo(s) lugar(es) de nacimiento y sepultura enseñaban con orgullo los cretenses ${ }^{84}$. Para Mellink, el culto a un dios-niño (un ser que estaba vinculado al ciclo de la vida y la muerte y que contaba con la asistencia de jóvenes nodrizas) se podría haber transmitido desde Creta (donde se creía que unas ninfas Gerestiadas criaron a Zeus), a Lacedemonia (donde Jacinto se acompañaba de las Jacintidas) y al Ática (donde las Jacintidas habrían sido consagradas a Geresto). En esta última región, existiría un lugar que era identificado como la Tumba de Geresto y que estaría ubicado sobre (o se asemejaría a) una colina.

Para Ervin ${ }^{85}$, «Geresto» es principalmente un topónimo predorio que pudo haber sido aplicado, incluso con pequeñas variaciones como «Gerestion», a distintas realidades geográficas. La investigadora cree, de hecho, que las ninfas Gerestás de la inscripción ática IG II ${ }^{2}, 4547$ también pudieron haber tomado su nombre de un topónimo afïn ${ }^{86}$. Además, identifica a las ninfas Gerestás con las Jacintidas y las Erecteídas. Ervin localiza la Tumba de Geresto en el Monte Jacinto e identifica este último con la llamada (por los arqueólogos) Colina de las Ninfas en Atenas, allí donde existía un santuario dedicado a estas divinidades menores ${ }^{87}$. La hipótesis «Tumba de Geresto y Jacintion en Monte Jacinto/Colina de las Ninfas» es secundada por expertos como Wycherley, Culley y Robertson. Robertson subraya además que la Colina de las Ninfas fue también la sede de un santuario de Zeus, por lo menos, en el s. IV a.C. El Crónida parece haber sido adorado aquí bajo la epíclesis «Meliquio», es decir, como un dios agrario, propiciador de la fertilidad ${ }^{88}$. A tenor de lo expuesto, se podría inferir que este cerro del asty de Atenas habría albergado un buen número de santuarios de divinidades agrarias, curotróficas y apotropaicas que quedaban vinculadas entre sí con lazos míticos: el héroe/dios de la vegetación Jacinto (homónimo del monte ateniense y propietario de un santuario ubicado probablemente allí mismo) tuvo unas hermosas y florecientes hijas (unas ninfas que también eran honradas en esta colina), las cuales fueron sacrificadas a Geresto (un ser imponente, que era familiar o asistente de Zeus, y cuyos restos descansaban en una tumba que pudo haberse alzado en el Monte Jacinto), para lograr que el Crónida (adorado como Meliquio en la Colina de las Ninfas) librase de la peste y la hambruna a los ciudadanos de Atenas ${ }^{89}$.

Como se aprecia, cada una de las hipótesis planteadas hasta ahora viene a aportar un enfoque nuevo, diferente, al estudio de los datos disponibles. De todas ellas, la propuesta

${ }^{84}$ Con relación a «la Tumba de Zeus» véase Istro (FGrH 334, F 48). Calímaco (Himno I, 8) desconfía de la veracidad de la leyenda. Sobre la cuestión A.B. Cook, Zeus. A study in ancient religion, Cambridge, 1914, Vol. I, pp. 157ss.; B.C. Dietrich, The Origins of Greek Religion, Berlin-New York, 1974, pp. 15-16, n. 78.

${ }^{85}$ M. Ervin, "Geraistai Nymphai Genethliai and the Hill of the Nymphs», Platon 21 (1959), pp. 146-159.

${ }^{86}$ Como apoyo a su hipótesis, Ervin remite a ejemplos como el de las musas/ninfas Ilisíadas de Atenas, que se denominaron así a partir del río Iliso. Véase Paus., I, 19, 5.

87 Tal y como atestigua la inscripción $\mathrm{IG} \mathrm{I}^{3}, 1065$, del s. V a.C.

${ }^{88}$ R.E. Wycherley, «Minor Shrines in Ancient Athens», Phoenix 24 (1970), p. 287; G.R. Culley, «The Restoration of Sanctuaries in Attica, II. The Structure of IG II², 1035 and the Topography of Salamis», Hesperia 46 (1977), p. 286 y n. 14; N. Robertson, Religion and Reconciliation..., op. cit., pp. 199-200, 206-212; J.L. Larson, Greek Nymphs..., op. cit., p. 131; G.V. Lalonde, Horos Dios ..., op. cit., pp. 42-46.

${ }^{89}$ La pregunta que surge inmediatamente a raíz de este enfoque es cuándo se forjaron estos lazos míticos. 
de Mellink es la única que, al considerar a Geresto como un «doble» de Zeus, permite atribuir una cierta lógica a la realización por parte de los atenienses de un sacrificio en honor de Geresto con el fin de contentar a Zeus, severo castigador de los áticos por la muerte de Androgeo (pues al ofrecer víctimas expiatorias al cíclope, de forma indirecta se estaría agasajando al Crónida). Por nuestro lado, ya hemos apuntado que nos parece muy convincente la caracterización de Jacinto y las Jacintidas como daimones propiciatorios de la regeneración, teniendo en cuenta su nombre y las distintas informaciones existentes sobre el culto del primero, principalmente en Esparta. En lo concerniente a Geresto, la mención de su tumba como el lugar donde se le conmemoraba nos lleva a considerarlo como una divinidad ctónica, ligada al ámbito de la muerte. Sin embargo, dada su condición de cíclope, nos mostramos menos propensos a creer que el campo de acción de Geresto englobara también la esfera del renacimiento tras la muerte o de la regeneración anual de la Naturaleza. La razón por la cual Geresto aparece en la Tradición $\mathrm{G}($ eresto) sigue constituyendo el gran enigma que se esconde tras el relato de [Pseudo]Apolodoro. No queda más que reconocer que, con los datos actualmente disponibles, la única manera de avanzar en la interpretación de esta historia es arriesgarse a andar en el terreno movedizo de la concatenación de conjeturas.

\section{LA TUMBA DE GERESTO}

En este mosaico en el que se adivinan figuras mitológicas sobre paisajes helenos hay, además, una tesela que parece desentonar en el espacio donde se la ha encajado hasta ahora. Nos referimos a la supuesta existencia de un cíclope (o de su tumba) en el Ática. En efecto, no tenemos constancia de ninguna otra tradición que sostuviera que un ser de esta estirpe vivió, actuó o murió en Atenas. Cierto es que los muros de la Acrópolis fueron erigidos en técnica ciclópea y que este aparejo, utilizado en múltiples construcciones de Grecia, se llamó así porque se creía que los cíclopes fueron sus inventores ${ }^{90}$. Sin embargo, la tradición popular consideraba que los muros protectores de la Acrópolis ateniense fueron obra, concretamente, de los pelasgios Argolas e Hiperbio ${ }^{91}$.

Las fuentes literarias suelen situar a los cíclopes en distintas regiones del Peloponeso ${ }^{92}$ y, sobre todo, en Eubea y en las zonas afectadas por la colonización euboica, como Sicilia ${ }^{93}$. El historiador del s. III a.C. Istro ubicaba a los cíclopes en Eubea, concretamente en un lugar llamado Teuquíon: estos seres inventaron allí las armas de bron-

\footnotetext{
90 Véanse los casos de Micenas (E., $H F, 943-947$ e $I A, 152,265$ y 1500-1501; también Paus., II, 16, 5) y Tirinto (Apollod., Bibl., II, 2, 1 y Paus., II, 25, 8).

${ }^{91}$ Pausanias (I, 28, 3) comenta que poco se sabía de ellos a excepción de que procedían de Sicilia. El hecho de que los cíclopes también fueran los habitantes míticos de esta isla no significa que Argolas e Hiperbio deban ser identificados, a su vez, como cíclopes.

92 Véase supra sobre su participación en la construcción de las murallas de Micenas y Tirinto.

93 Sobre Sicilia, Th., VI, 2 (en donde se hace alusión a poetas anteriores al propio Tucídides que ubicaban a los cíclopes en esta isla) y Str., I, 2, 9, entre otros.
} 
$\mathrm{ce}^{94}$. Por su parte, Cayo Julio Solino afirmaba que Briareo (un centimano según ciertas tradiciones pero un cíclope según otras ${ }^{95}$ ) recibía culto en Caristo ${ }^{96}$, ciudad euboica cuya chora englobó seguramente la cercana kome Geresto. En fin, basándose en un fragmento de Estrabón $(X, 1,10)$, A. Mele ha deducido que dentro de los límites geográficos de Eubea circuló una leyenda que sostenía que Admeto fundó un santuario de Apolo en la zona central de la isla, en conmemoración del asesinato de los cíclopes a manos de Apolo ${ }^{97}$. A tenor de todo lo dicho hasta ahora, ¿resulta totalmente descabellado pensar que, en la imaginería helena, la Tumba de Geresto citada por [Pseudo]Apolodoro pudo haber sido localizada en la kome Geresto de Eubea?. La descripción de Eurípides de este paraje euboico como un entorno casi inaccesible ${ }^{98}$ nos remite de nuevo al campo temático de lo marginal que domina en la Tradición G. En efecto, si a un ámbito marginal (un oráculo) se dirigieron los atenienses para buscar la respuesta a sus problemas; y si en un ámbito marginal (por su edad, procedencia y condición social) se ubican las víctimas elegidas para expiar el miasma, ¿por qué no concebir que el sacrificio de las hijas de Jacinto se realizó en un territorio igualmente marginal?.

En varios relatos sobre pharmakoi se habla del exilio o expulsión de éstos más allá de los límites territoriales de la ciudad que los eligía ${ }^{99}$. En la propia leyenda sobre la ofrenda humana a Minos vemos que finalmente los atenienses se vieron obligados a enviar a las víctimas expiatorias del asesinato de Androgeo a la lejana isla de Creta, allende del mar. De igual manera, las muchachas que los locrios ofrecían a Atenea para redimirse de la culpa de Áyax partían de Grecia Central rumbo a Troya en un barco que atravesaba el Egeo ${ }^{100}$. Asimismo tenemos constancia de una categoría de pharmakoi, los peripsemata, que eran introducidos en el mar (ipero sumergidos en el agua o embarcados en botes?) en el marco de un ritual de expiación oficiado cuando varias adversidades afligían una comunidad ${ }^{101}$. En Léucade, el pharmakos era arrojado al mar desde un precipicio y luego se le recogía en una barca para expulsarlo, preferentemente vivo, fuera de los límites del territorio de la ciudad ${ }^{102}$.

Consideremos por un momento la posibilidad de que el cíclope Geresto de la Tradición $\mathrm{G}$ fuera, en efecto, el mismo personaje que Esteban de Bizancio retrata como hijo de Zeus y héroe epónimo de la kome Geresto en Eubea. En tal caso, en el fragmento de [Pseudo]Apolodoro se podría estar insinuando que los atenienses, al sufrir distintas calamidades, centraron inicialmente su atención en buscar un remedio a los castigos que les enviaba exclusivamente Zeus, es decir, la peste y la hambruna,

\footnotetext{
${ }^{94}$ Istro, FGrH 334, F 71.

${ }^{95}$ Hes., Th., 147-153 y Demetrio de Calátide, FGrH 85, F 4.

${ }^{96}$ Cayo Julio Solino, Colección de hechos memorables, XI, 6.

97 A. Mele, «I ciclopi, Calcodonte e la metallurgia calcidese», en V.V.A.A., Nouvelle Contribution à l'étude de la société et de la colonisation eubéennes (Cahiers du Centre Jean Bérard, 6), Naples, 1981, p. 22. También id., Il commercio greco arcaico. Prexis ed emporie, Napoli, 1979, p. 37 y n. 78.

98 E., Cyc., 290-295.

${ }^{99}$ Así, para Abdera, Call., Fr. 90 Pfeiffer; Diegesis, II, 29-40.

100 Tal y como apuntan Licofrón (Alejandra, 1141-1173) y [Pseudo]Apolodoro (Ep., 6, 20-22).

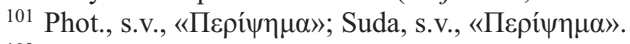

102 Str., X, 2, 8-9.
} 
sin tener quizás conocimiento de que ambos males, pese a tener un origen divino, habían sido instigados por el propio Minos. El primer oráculo al que se habrían remitido los atenienses podría haberles instado a «dar satisfacción al hijo del Crónida». El consejo sería, por lo tanto, acertado. Sin embargo, los atenienses podrían haberlo malinterpretado y, en vez de contentar a Minos, se habrían prestado a realizar sacrificios en honor de Geresto, otro de los vástagos del Crónida. Tal vez la Tradición G contó con un «prólogo», hoy perdido, en el que se postulaba que los atenienses habían asesinado (con anterioridad a Androgeo) a Geresto y que, al ser castigados por Zeus, atribuyeron erróneamente sus males a esta acción. Los atenienses se habrían dado cuenta de su interpretación errónea de la respuesta mántica solamente al ver que el sacrificio en la Tumba de Geresto no había servido de nada. De ahí que repitiesen la consulta.

Al hilo de todo lo dicho, quisiéramos agregar, en primer lugar, que no debe provocar sorpresa la existencia de una tumba de un cíclope en la sede de un santuario de Poseidón (en el caso euboico, de Poseidón Gerestio): como atestigua Pausanias, en el santuario del dios del mar que se alzaba en Istmia había un altar dedicado a estas criaturas ${ }^{103}$. Igualmente es interesante comprobar que en el Athis de Filócoro ( $F G r H$ 328 F 30) y en la Constitución de los Atenienses atribuida a Aristóteles (XXII, 3-8) queda de manifiesto que el enclave euboico de Geresto constituía una posición liminar en relación a Atenas y, sobre todo, un punto geográfico de referencia para mecanismos importantísimos de protección de la vida política de los habitantes del Ática. A partir de estos relatos sabemos que todo ciudadano ateniense condenado al ostracismo (por temerse que su enorme influencia provocase una situación extrema de guerra civil) había de abandonar la polis en un periodo de unos diez días desde que la asamblea hubiese decidido su expulsión. Hacia el este, el punto más cercano a Atenas en el que podía instalarse era, precisamente, Geresto ${ }^{104}$. La ciudad expulsaba fuera de sus límites al principal representante (de nuevo nos encontramos con el concepto del pars pro toto) de lo que se adivinaba como una posible amenaza, con el fin de prevenir una transgresión del orden establecido. El ciudadano que era elegible en un proceso de ostracismo constituía una figura que se encontraba en una posición liminar, en tanto y cuanto que poseía, tal y como apunta Plutarco en sus biografías de

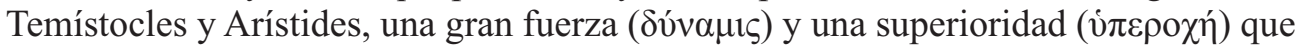

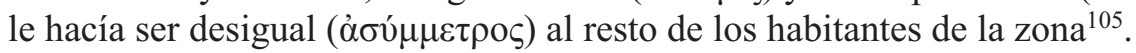

\footnotetext{
103 Paus., II, 2, 1.

104 Sobre estas delimitaciones geográficas concernientes al ostracismo, T.J. Figueira, «Residential Restrictions on the Athenian Ostracized», GRBS 28 (1987), pp. 282-305 (reeditado en T.J. Figueira, Excursions in Epichoric History. Aiginetan Essays, Maryland, 1993, pp. 173-196). Sobre el periodo cronológico en el cual se aplicó la medida del ostracismo, véase H. Heftner, «Ende und "Nachleben" des Ostrakismos in Athens», Historia 52 (1) (2003), pp. 23-38 y E. Giugni, Problemi cronologici relativi all'ostracismo alla luce di nuovi ritrovamenti di Chersonesos Taurica, Firenze, 2004. Sobre el ostracismo en general, S. Brenne, Ostrakismos und Prominenz in Athen. Attische Bürger des 5. Jhs. v. Chr. auf den Ostraka, Wien, 2001.

${ }^{105}$ En la Constitución de los Atenienses (XXII, 6) se apunta que el proceso de ostracismo podía ser usado contra todo ateniense que podía parecer « $\mu \varepsilon i \zeta \zeta \omega v »$, enorme. En la Política de Aristóteles (V, 3, 1302b) se
} 


\section{LA OFRENDA ADECUADA}

La Tradición G termina con el reconocimiento de que la situación de los atenienses no mejoró en lo más mínimo tras el sacrificio de las hijas de Jacinto en la Tumba de Geresto. Como apuntamos en la introducción, en la mitografía griega no encontramos muy a menudo una confesión sobre la ineficacia total de un asesoramiento oracular. De hecho, podemos contrastar las palabras de [Pseudo]Apolodoro con la versión del mito sobre las consecuencias de la muerte de Androgeo que transmite Diodoro (IV, 60-61). Según el historiador siciliano, la peste y la esterilidad de los campos afectaron no sólo al Ática, sino a toda Grecia. De ahí que las comunidades helenas se remitieran en conjunto al oráculo de Apolo y luego, a instancias de éste, a Éaco, el hijo de Zeus y Egina. Los sacrificios realizados por Éaco produjeron el cese de la peste en la Hélade con la única salvedad del Ática, pues la culpa de esta última zona exigía de una expiación más rigurosa. Es decir, en el relato de Diodoro las indicaciones divinas se revelan fructíferas, aunque su resultado no fuese global. En la Tradición G las esperanzas atenienses de una solución a los males que se ciernen exclusivamente sobre el Ática quedan frustadas por completo. Se hace necesaria una nueva consulta al oráculo para dar con el remedio definitivo.

En el fragmento de [Pseudo]Apolodoro podemos ver, a pesar de todo, que la Tradición $\mathrm{G}$ se imbrica con lograda armonía con el colofón de la historia sobre la ofrenda humana por la muerte de Androgeo: a saber, el envío de jóvenes atenienses a Creta. En efecto, a lo largo del relato del mitógrafo descubrimos un crescendo cuantitativo y cualitativo (por lo que se refiere al status social) de las víctimas entregadas para la expiación del miasma. Así, en una primera fase (retratada por la Tradición G) se sacrifican a las hijas de un extranjero, que son cuatro. En una segunda fase (aludida también por [Pseudo]Apolodoro) se manda a Creta a los vástagos de ciudadanos atenienses, en un número de catorce. Y en una última fase (la leyenda más difundida), se suma a los catorce (o trece) un personaje más, que es Teseo, un héroe, un hijo del rey ateniense ${ }^{106}$. Si la hipótesis anteriormente planteada sobre la ubicación de la Tumba de Geresto en Eubea fuese, además, correcta, entonces también podría observarse un crescendo topográfico en el que gradualmente los pharmakoi eran alejados aún más de la comunidad que aspiraba a la purificación: quizás aquí surgiese la idea de que cuanto más patente resultaba la expulsión de los individuos que cargaban con la culpa colectiva, mayores posibilidades tenía la comunidad afectada de asegurarse el resultado deseado. Encontramos, en fin, un paralelismo en las características del receptor de los sacrificios, pues tanto el cíclope Geresto como el Minotauro cretense son criaturas marginales, semihumanas y antropófagas.

transmite la idea de que el ostracismo constituía un mecanismo excepcional, un remedio extremo a circunstancias que, en realidad, debían ser prevenidas, evitadas con antelación, mediante otros procedimientos. En la misma obra se habla de los condenados al ostracismo como individuos que habían acaparado un poder enor-

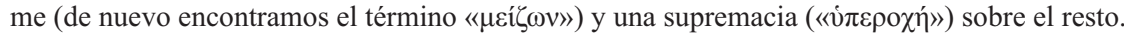

${ }^{106}$ Diodoro dice (IV, 61) que Teseo se encontraba en la segunda tanda de jóvenes enviados a Creta. Por el contrario Plutarco (Thes., XV) apunta que el héroe formó parte de la tercera ofrenda humana al Minotauro. 


\section{EXPLOTANDO UN MITO}

Al igual que ocurre con el resto de los mitos helenos, la Tradición G conforma un relato que, al ser ubicado en un contexto histórico, deja de revelarse como una simple producción estética y se vislumbra como un poderoso instrumento con múltiples utilidades prácticas. Pues al servicio de los intereses atenienses resultaba sin duda idóneo, por su poder conmovedor y simpatético y su capacidad de difusión y transmisión, para ejemplarizar, aleccionar, encumbrar y justificar. Así, la función más evidente de la Tradición $\mathrm{G}$ parece haber sido la plasmación de un modelo de conducta para los habitantes del Ática, un paradigma del buen ciudadano o meteco que, en momentos de necesidad, no duda en anteponer el bien general de la comunidad al suyo propio. Y en efecto, la actitud heroica de las hijas de Jacinto es recordada y expuesta como un ejemplo a imitar por Foción después de la destrucción de Tebas en el 335 a.C. ${ }^{107}$

Asimismo resulta evidente la explotación propagandística de la Tradición G y, en general, de toda la historia sobre la ofrenda humana a Minos, con vistas a la (auto)glorificación ateniense. De hecho, y a pesar de que se reconoce la aberración que supone el crimen de Androgeo, origen de los males del Ática, el relato encumbra la valentía y la excelencia militar de los atenienses, en tanto y cuanto que fueron capaces de hacer frente a las tropas del hegemón del momento, Minos. Únicamente los estragos que provocan los castigos divinos (y no los humanos) les llevan a rendir pleitesía al cretense. Además, se contrasta la probidad, aunque sea impuesta, de las hijas de Jacinto (al fin y al cabo, éstas consienten en ser sacrificadas en beneficio de la comunidad en la que residen) con la laxitud ética de la hija del rey de Mégara (una joven que no había dudado en sacrificar patria y familia en beneficio propio) ${ }^{108}$. En una primera fase, el ensalzamiento podría quedar atemperado por la condición no ateniense de las víctimas inmoladas, las hijas de Jacinto, pero luego se manifestaría plenamente, en una segunda fase, cuando la ofrenda humana viniese a quedar constituida completamente por los hijos e hijas de los mismísimos ciudadanos áticos.

La Tradición G también pudo haber sido utilizada para justificar el nombre del demos ático Lusia, tal y como se infiere de una información de Esteban de Bizancio ${ }^{109}$. El lexicógrafo comenta que Lusiá o Lusia, una hija de Jacinto, dio nombre a esta demarcación territorial de la tribu de los Oineis. La genealogía plasmada por Esteban de Bizancio lleva a identificar la heroína epónima Lusia con la Litea de [Pseudo]Apolodoro. En cuanto al demos Lusia, éste es situado por J.S. Trail en el valle de Cefiso ${ }^{110}$. A. Mele parece contemplar la posibilidad de que el supuesto sepulcro de Geresto, un heroon, se hubiese alzado en el demos Lusia ${ }^{111}$. Por el contrario, E. Kearns considera invero-

\footnotetext{
107 D.S., XVII, 15, 2.

${ }^{108}$ Esta comparación queda acentuada por la estrecha relación familiar que unía a Egeo, rey de Atenas, y a Niso, rey de Mégara. [Pseudo]Apolodoro (Bibl., III, 15, 5-8) y Pausanias (I, 19, 4) nos informan que eran hermanos o hermanastros.

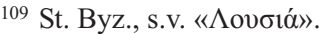

110 Sobre Lusia, J.S. Traill, The Political Organization of Attica. A Study of the Demes, and Phylai, and their Representation in the Athenian Council, Princeton, 1975, p. 49.

111 A. Mele, «I ciclopi, Calcodonte ...», op. cit., p. 21.
} 
símil la etiología de Esteban de Bizancio: en su opinión, resulta más que cuestionable que la circunscripción hubiera tomado su nombre de una única hija de Jacinto, por cuanto que ésta difícilmente pudo haber tenido entidad cultual propia fuera de la tétrada de hermanas ${ }^{112}$.

A más de esto, la Tradición $\mathrm{G}$ ha sido considerada como un mito etiológico que explicaría la instauración en Atenas de un culto a las Jacintidas ${ }^{113}$. El problema que surge aquí es que en el texto de [Pseudo]Apolodoro no se afirma que se hubiera fundado culto alguno a raíz del sacrificio celebrado sobre la Tumba de Geresto. Por el contrario, en el Erecteo de Eurípides sí que se plasma de forma clara cómo, una vez acontecida la muerte de las Jacintidas, es decir, de las hijas de Erecteo, la diosa Atenea ordenó a los atenienses la consagración, en honor de las jóvenes, de un temenos que había de tener la consideración de ábaton. En el recinto sacro debían realizarse asimismo sacrificios anuales de toros. Además, grupos de muchachas habían de ejecutar danzas conmemorativas. Excepcionalmente, cuando la ciudad se encontraba en guerra con algún enemigo, las Jacintidas debían recibir libaciones de agua y miel. Como hemos apuntado arriba, contamos también con una inscripción de finales del s. V a.C., que alude a ciertas ofrendas en honor de las Jacintidas, y con otro epígrafe del s. I d.C., que cita un altar Jacintion. El escollo que se plantea aquí quedaría automáticamente superado si en la concepción de los antiguos atenienses, las Jacintidas que eran hijas de Jacinto y que murieron en época de Egeo, y las Jacintidas que eran hijas de Erecteo y que se inmolaron en época de la guerra contra Eumelo, constituían, a efectos cultuales, las mismas entidades a adorar, y eso a pesar de que a efectos narrativos estaríamos ante una disyuntiva cronológica (pues en la secuencia de la monarquía mítica ateniense el reinado de Erecteo precede al de Egeo en varias generaciones).

Es importante subrayar, por otro lado, que la historia general de la ofrenda humana a Minos engloba un buen número de acciones míticas que sirvieron de aitia a rituales áticos. Así, la consagración en honor a Apolo que realizó Teseo antes de partir rumbo a Creta dio origen, en opinión de los atenienses, a la celebración de una procesión anual de doncellas atenienses que tenía como meta el Delfinion local ${ }^{114}$. De forma análoga, la parada en Delos que hicieron Teseo y sus compañeros cuando retornaban a Atenas desde Creta fue considerada como el germen de la theoría anual que los atenienses enviaban a Delos, probablemente ya en época de Solón y sin duda alguna en los periodos clásico y helenístico ${ }^{115}$. En fin, los honores que Teseo rindió

\footnotetext{
112 E. Kearns, The Heroes of Attica, op. cit., pp. 102, 181-182.

113 Sobre esta interpretación, véase U. von Wilamowitz-Moellendorff, Der Glaube der Hellenen, I, Berlin, 1931 , p. 106.

114 Véase Plu., Thes., XVIII, 1-2. Al respecto, C. Calame, Thésée et l'imaginaire athénien. Légende et culte en Grèce antique, Lausanne, 1990, p. 143; R. Parker, Polytheism and Society at Athens, Oxford, 2005, pp. 208-209.

115 Pl., Phd., 58a-c y X., Ap., IV, 8, 2. Véase C. Calame, Choruses of Young Women in Ancient Greece, New York-London, 1997, pp. 108-109; R. Parker, Polytheism and Society at Athens..., op. cit., pp. 81-82; V. Chankowski, Athènes et Délos à l'époque classique. Recherches sur l'administration du sanctuaire d'Apollon délien, Paris, 2008, pp. 86-106
} 
tras su retorno a Atenas a los comandantes de su barco, Nausítoo y Feacio, devinieron, a decir de los atenienses, en las Cibernesia, unas fiestas vinculadas a la navegación ${ }^{116}$.

Muchos de los elementos de la Tradición G nos remiten, además, a los llamados «mitos de iniciación»: entre ellos, la alusión a unas jóvenes que asumen la obligación de prestar un servicio a la comunidad en la cual residen, la presencia de elementos florales, o la indicación sobre la muerte colectiva del grupo de doncellas. El protagonismo de un ser monstruoso, que en nuestro caso no es otro que un cíclope, también encuentra paralelos en varios relatos de este tipo ${ }^{117}$. Creemos que no nos equivocamos si incluimos la historia sobre el sacrificio de Anteide, Egleide, Litea y Ortea en el segundo o en el tercer subgrupo de la clasificación propuesta por Graf para los «mitos de iniciación» ${ }^{118}$. El tercer subgrupo de Graf corresponde, de hecho, a los «mitos de iniciación» que, «in the ancient documentation, are not connected with rituals at all but are being read by modern scholars as having an initiatory background [which] belongs to the prehistory of these myths ${ }^{119}$. Y en efecto, en el texto de [Pseudo]Apolodoro no tenemos (lo hemos visto) ninguna referencia explicita a la institución de un ritual cuyo fundamento hubiese sido la inmolación de las hijas de Jacinto. Por otro lado, las semejanzas entre el mito de las Vírgenes Locrias y la Tradición G nos impulsarían a considerar esta última como un «purification or atonement rite» que quizás habría evolucionado hasta conformar un mito de iniciación: una categoría de construcciones míticas que Graf reúne en su segundo subgrupo.

Finalizamos el presente apartado sobre los usos de la Tradición G planteando una última hipótesis. En otro estudio ${ }^{120}$ nos referimos a la posibilidad de que Atenas hubiese controlado, a partir del periodo clásico y en los momentos en que su talasocracia era indiscutible, el puerto de Geresto en Eubea. Uno de estos momentos quizás empezó tras la conclusión de la guerra que, entre el 476 y el 469 a.C., enfrentó a Atenas con Caristo. Es entonces cuando un grupo de clerucos áticos pudo haberse instalado en la zona. En caso de admitir tal supuesto, cabría preguntarse si los atenienses utilizaron la Tradición G para justificar precisamente este dominio, alegando que en tiempos del reinado de Egeo ellos ya habían rendido honores al personaje homónimo (¿y fundador mítico?) del enclave euboico. Como apunta Th. Figueira ${ }^{121}$, los mecanismos de justificación de la hegemonía ateniense del periodo clásico recurrieron ampliamente al uso de construcciones y reelaboraciones mitológicas para alcanzar sus objetivos. Así lo vemos, verbigracia, en el caso de la apropiación de Esciros (476-475

\footnotetext{
116 Philoch., FGrH 328, F 111 (= Plu., Thes., XVII, 6-7). Sobre estas fiestas, R. Parker, Athenian Religion: A History, Oxford, 1996, pp. 314-315 e id., Polytheism and Society at Athens..., op. cit., p. 410 y n. 95 , p. 475.

${ }^{117}$ Al respecto, A. Brelich, Paides e Parthenoi, op. cit., pp. 37 y 89, n. 113.

${ }^{118}$ F. Graf, «Initiation. A concept with a troubled history», en D.B. Dodd y C.A. Faraone (ed.), Initiation in Ancient Greek Rituals and Narratives. New Critical Perspectives, London-New York, 2003, pp. 3-24.

119 F. Graf, «Initiation...», op. cit., p. 15.

${ }^{120}$ M. Arjona Pérez, «Eubea e imperialismo ateniense: un acercamiento a aspectos religiosos», en J.M. Cortés Copete et al. (ed.), Grecia ante los Imperios, en prensa.

121 Th. Figueira, «Colonization in Classical Period», en G.R. Tsetskhladze (ed.), Greek Colonisation. An Account of Greek Colonies and other settlements overseas. Volume II, Leiden-Boston, 2008, pp. 454ss.
} 
a.C.), una empresa respaldada por un pretexto mitológico que contiene varios elementos también presentes en la Tradición G. En efecto, según transmite Plutarco, el oráculo de Delfos había instado a los atenienses a que localizaran la Tumba de Teseo en Esciro y a que transportaran los restos mortales del héroe al Ática; una cosa que no pudo hacerse hasta que la isla fue conquistada por Cimón, dado que con anterioridad los autóctonos, inhospitalarios y salvajes, habían impedido a los atenienses la búsqueda de las reliquias ${ }^{122}$. Por otro lado, no fueron pocas las historias proatenienses que reivindicaban una precedencia de los habitantes del Ática en la instauración de cultos a héroes y conceptos divinizados. Pausanias se hace eco de algunos de estos rela$\operatorname{tos}^{123}$, y de ahí que destacase a los atenienses, entre todos los helenos, por su mayor celo religioso $^{124}$.

\section{CONCLUSIÓN}

A partir de este mosaico, en el cual discernimos cuatro ámbitos (Ática, Creta, Lacedemonia y Eubea), cuatro protagonistas principales (los atenienses, Minos, Jacinto y Geresto) y cuatro jóvenes «invitadas» (Anteide, Egleide, Litea y Ortea) pero del que apenas conseguimos extraer certidumbres, nosotros hemos intentado vislumbrar ciertas líneas de síntesis que, creemos, permiten la combinación lógica de algunos elementos presentes en el relato de [Pseudo]Apolodoro. No se nos escapa que aún quedan muchas cuestiones por esclarecer. Para desentrañar algunas de ellas no queda otra que esperar al descubrimiento de nuevos documentos epigráficos y/o papiráceos que arrojen luz al respecto. Así, por ejemplo, desconocemos de qué fuente o fuentes se sirvió el autor de la Biblioteca para informarse sobre lo que nosotros hemos llamado la Tradición G. Diodoro apunta que Foción aludió a la inmolación de las hijas de Jacinto en uno de sus discursos ${ }^{125}$. Esto permite pensar que la historia era ya célebre antes de las décadas centrales del s. IV a.C. Pero ¿cuándo fue gestada concretamente y a raíz de qué evento?.

La concomitancia de un conflicto bélico, una peste y una escasez agraria retratada en el relato mitológico encuentra un paralelo histórico en la situación extrema a la que se enfrentaron los atenienses en el 430-429 a.C., cuando los peloponesios, durante la Guerra Arquidámica, asolaron las cosechas del Ática y una plaga mermó la población de Atenas. La identificación del mítico caudillo de los atenienses Egeo como responsable de los males del Ática, por incurrir en una acción impía y provocar las represalias de un poderoso enemigo meridional, recuerda, igualmente, la acusación dirigida hacia la persona de Pericles por sus conciudadanos cuando éstos le conside-

\footnotetext{
122 Plu., Thes., XXXV, 5 - XXXVI, 2 y Cim., VIII, 3-6.

123 Véase así el caso de Heracles en Maratón (I, 15, 3 y 32, 4) o de Anfiarao en la Oropia (I, 34, 2), en lo concerniente a la primera práctica, esto es, a la divinización de personajes con poderes sobrenaturales. Sobre la deificación de nociones como la Piedad, el Pudor, la Fama o el Impulso véase Paus., I, 17, 1 y $24,3$.

124 Paus., I, 17, 1 y 24, 3.

125 D.S., XVII, 15, 2.
} 
raron el principal fomentador de la política que desencadenó la guerra contra los peloponesios y le atribuyeron la culpa primordial de sus penurias ${ }^{126}$. Por otro lado, el hecho de que en la Tradición G se postulase que unas jóvenes de estirpe lacedemonia se prestaron a ser sacrificadas para lograr la redención de los atenienses nos lleva a pensar que esta tradición podría haber sido ideada en un momento en que era concebible que los espartanos y los atenienses mantuviesen relaciones amistosas.

La enigmática Tradición $\mathrm{G}$ es uno de los numerosos mitos helenos que han llegado hasta nosotros incidentalmente como anexos de relatos que gozaron de mayor fama. Aunque [Pseudo]Apolodoro se limitó a transmitir únicamente los detalles más básicos de esta leyenda, un análisis de su contenido nos ha llevado a abordar una amplia gama de aspectos sumamente relevantes de la religión griega: entre ellos, la popularidad que tenían los oráculos, aun cuando era conocida la posibilidad de que sus consejos resultasen ineficaces, o la multiplicidad (pero en el marco de una evidente homogeneidad) de los mitos y los rituales de expiación, o incluso la gran difusión de los cultos a divinidades menores vinculadas al ciclo regenerativo de la Naturaleza. El estudio del testimonio de [Pseudo]Apolodoro también nos permite apreciar la enorme complejidad de las elaboraciones mitológicas helenas, unas construcciones en las que a menudo afloran nociones y entidades ambivalentes ${ }^{127}$ y fronteras geográficas, pero también temáticas, permeables ${ }^{128}$.

\footnotetext{
${ }^{126}$ Véase al respecto, Th., II, 59-65; D.S., XII, 45, 1-5; Plu., Per., XXXV, 3-4.

127 Veáse, en nuestro caso, la confusión de personajes como las Jacintidas/Erecteídas/Gerestiadas, o los antropónimos/topónimos Geresto o Jacinto.

${ }^{128}$ Pues los márgenes del marco de acción espacial y facultativa de seres como Jacinto y Geresto quedan diluidos.
} 